\title{
LA (IN)DEPENDENCIA DEL PODER JUDICIAL EN POLONIA. SOBRE LA SUBORDINACIÓN DE LOS JUECES AL PODER POLÍTICO ${ }^{1}$
}

\author{
ANNA CHMIELARZ-GROCHAL \\ Profesora de Derecho constitucional \\ Universidad de Lodz, Polonia \\ JAROSŁAW SUŁKOWSKI \\ Profesor de Derecho constitucional \\ Universidad de Lodz, Polonia
}

TRC, n. ${ }^{\circ} 47,2021$, pp. 297-322

ISSN 1139-5583

\begin{abstract}
SUMARIO
I. Introducción. II. El poder judicial en Polonia: un esbozo del sistema. III. Amenazas al poder judicial. IV. Los cambios personales. V. Los cambios sistémicos y de organización. VI. La politización del proceso de nombramiento de los jueces. VII. Un nuevo régimen disciplinario. VIII. Injerencia en el ámbito de la libertad y los derechos de los jueces. IX. Recapitulación.
\end{abstract}

\section{INTRODUCCIÓN}

En el enfoque tradicional de la separación de poderes el poder judicial es contemplado como una autoridad independiente. Aunque la división de poderes habilita diversos mecanismos de interacción mutua de sus segmentos individuales, el poder judicial dispone de la mayoría de los poderes inhibitorios y de control. La implementación de competencias de control requiere asegurar la separación personal, organizacional y funcional del poder judicial. Sin embargo, los efectos de las posibles distorsiones provocadas por la tensión entre la autoridad política (legislativa

${ }_{1}$ Este trabajo se enmarca en el proyecto de investigación n. ${ }^{\circ}$ 2017/27 / L / HS5 / 03245 «La conciencia constitucional como remedio a la crisis del discurso y el déficit de democracia en la Unión Europea», financiado por el Centro Nacional de Ciencia - DEC-2017/27 / L / HS5 / 03245—. 
y ejecutiva) y judicial van más allá de la dimensión institucional. No debe olvidarse el fundamental papel de los tribunales de ser garantes de la protección de los derechos individuales. La injerencia en la independencia del poder judicial reduce el estándar de esta protección y socava la confianza del individuo en el Estado.

En Polonia, en los últimos años, son claros los ejemplos de expansión de la influencia del poder político sobre el poder judicial. Las actividades de los poderes legislativo y ejecutivo han afectado a muy variadas cuestiones: estructura del poder judicial (Tribunal Supremo, tribunales ordinarios, tribunales militares), ámbito de competencia (Tribunal Supremo, Tribunal Administrativo Supremo, tribunales ordinarios), alcance de las competencias de algunos órganos estatales con respecto a los tribunales (Ministro de Justicia, Presidente, Consejo Nacional de la Magistratura), personal (Tribunal Constitucional, Tribunal Supremo, Consejo Nacional de la Magistratura, presidentes de tribunales ordinarios), y al proceso de designación de los jueces, a su responsabilidad disciplinaria y a numerosas restricciones de sus libertades y derechos, como la libertad de expresión o la libertad de asociación, por citar alguno.

El período de cambios fue extremadamente dinámico; una docena de leyes fueron aprobadas, a menudo en cuestión de días o incluso de horas. Es interesante apuntar que hasta en dos ocasiones el Presidente se negó a firmar los proyectos de ley presentados. Desde el ámbito político se llevaron a cabo numerosas acciones que desestabilizaron el poder judicial (denegación a aceptar el juramento de los jueces constitucionales seleccionados, intentos de remoción de presidentes de tribunales, inicio de procedimientos disciplinarios por remitir cuestiones prejudiciales al Tribunal de Justicia de la Unión Europea). Todas estas actividades provocaron graves perturbaciones en el funcionamiento del poder judicial tanto en la dimensión institucional (por ejemplo, una parálisis de dos años en el funcionamiento del Tribunal Constitucional) como en la jurisdicción (perturbación de la uniformidad de la jurisprudencia). La crisis del poder judicial en Polonia se ha convertido en un tema de interés no solo por supuesto en Polonia, sino también en Europa donde se ha visto como un ataque al Estado de derecho ${ }^{2}$. Sobre estas

2 Vid. en esta misma revista, KRzYwoń, A., «La crisis constitucional en Polonia (2015-2017): cómo cuestionar el sistema del equilibrio constitucional en dos años», TRC, n. ${ }^{\circ} 41,2018$, pp. 359-379. También, sin ánimo exhaustivo; RADZIEwICZ, P., «Refusal of the Polish Constitutional tribunal to apply the act stipulating the constitutional review procedure», Review of Comparative Law, n. ${ }^{\circ} 1$ (28), 2017, pp. 23-40; SADURSKI, W., Poland's constitutional breakdown, Oxford University Press, Oxford, 2019; Kelemen, R.D. y Pech, L., «The uses and abuses of constitutional pluralism: undermining the rule of law in the name of constitutional identity in Hungary and Poland», Cambridge Yearbook European Legal Studies, n. ${ }^{\circ}$ 21, 2019, pp. 59-74; SAdursKi, W., «How democracy dies (in Poland): a case study of anti-constitutional populist backsliding», Revista Forumul Judecãtorilor, n. ${ }^{\circ}$ 1, 2018, pp. 104-178; JAnkovic, S., "Polish Democracy under Threat? An Issue of Mere Politics or a Real Danger?», Baltic Journal of Law E Politics, n. ${ }^{\circ}$ 9(1), 2016, pp. 49-68; JAREMBA, U., «The Rule of the Majority vs the Rule of Law: How Poland Has Become the New Enfant Terrible of the European Union», Tijdschrift voor Constitutioneel Recht, n 7, 2016, pp. 262-274; BUGARIČ, B., «Central Europe's descent into autocracy: A constitutional analysis of authoritarian populism», International Journal of Constitutional Law, n. ${ }^{\circ}$ 17, 2019, pp. 597-616; DrinocZI, T. y Bień-KACA£A, A., «Illiberal 
reformas se han vertido comentarios muy críticos por parte del Tribunal de Justicia de la Unión Europea, la Comisión Europea, el Parlamento Europeo o la Comisión de Venecia. Encontrándose en pruebas este trabajo (marzo de 2021), la Comisión Europea ha anunciado que volverá a llevar ante el TJUE la reforma del Poder judicial.

\section{EL PODER JUDICIAL EN POLONIA: UN ESBOZO DEL SISTEMA}

El poder judicial es ejercido por las cortes y los tribunales (art. 173 de la Constitución de Polonia —en adelante $\mathrm{CP}$-) : Tribunal Supremo, tribunales ordinarios, tribunales administrativos y tribunales militares (art. 175 CP). Históricamente, los tribunales administrativos y militares han sido considerados como tribunales especiales debido al alcance de su jurisdicción. Además, la Constitución permite la posibilidad de establecer un tribunal excepcional o un procedimiento determinado para examinar casos ante un tribunal, pero solo en tiempos de guerra.

La Constitución establece el principio judicial de justicia, lo cual enfatiza la relación especial entre los tribunales y la protección de los derechos individuales (art. 175.1 CP). Encargar a los tribunales la administración de justicia garantiza la correcta y justa resolución de los casos, bajo la autoridad del Estado. La implementación de esta garantía, la facilitan las normas específicas de administración de justicia y garantías de independencia de tribunales y jueces.

De conformidad con el principio constitucional de independencia y distinción, el sistema de tribunales debe permanecer independiente de otros órganos estatales. La independencia se refiere tanto al nombramiento de los jueces como al ejercicio de la función jurisdiccional. La influencia de otros órganos estatales en la designación de puestos de los jueces debe ser limitada. Las decisiones en materia de personal deben depender de la obtención de un informe o de la presentación de una solicitud pertinente por parte de un órgano de autogobierno judicial o un órgano compuesto principalmente por representantes del poder judicial (Consejo Nacional de la Magistratura). Los órganos de otras autoridades tampoco pueden influir en el contenido de las decisiones judiciales. La supervisión de la actividad de los tribunales ordinarios y militares en el ámbito de su jurisdicción (la supervisión judicial), la realiza el Tribunal Supremo y, en el caso de los tribunales administrativos provinciales, el Tribunal Administrativo Supremo. La revisión de las decisiones judiciales se basa en el principio de primera instancia,

Constitutionalism: The Case of Hungary and Poland», German Law Journal, n. . 20, 2019, pp. 1140-1166; Zıółkowski, M., «Insight EU Court of Justice Standing up to Illiberal Democracy: Polish Judicial "Reforms" on Trial Two Faces of the Polish Supreme Court After "Reforms" of the Judiciary System in Poland: The Question of Judicial Independence and Appointments», European Papers, n. ${ }^{\circ}$ 5, 2020, pp. 347-362; CHMIELarz-Grochal, A. y SuŁkowski, J., «Appointment of Judges to the Constitutional Tribunal in 2015 as the Trigger Point for a Deep Constitutional Crisis in Poland», Przegląd Konstytucyjny, n. ${ }^{\circ}$ 2, 2018, pp. 91-119. 
y solo pueden ejercerla las autoridades judiciales. La injerencia de otras autoridades solo puede afectar a la actividad extrajudicial de los tribunales. La supervisión de la actividad administrativa de los tribunales ordinarios y militares la ejerce el Ministro de Justicia, y las actividades de supervisión administrativa no pueden interferir con un área donde los jueces son independientes ${ }^{3}$. La supervisión administrativa de los tribunales administrativos está a cargo del Presidente del Tribunal Administrativo Supremo.

El principio de independencia judicial está indisolublemente ligado al principio de autonomía de los jueces (art. 178.1 CP). La autonomía del poder judicial (en el sentido organizativo y funcional) crea la base para la independencia judicial, mientras que la independencia judicial es uno de los aspectos clave de un poder judicial autónomo. Al mismo tiempo, estos principios sirven para implementar el derecho constitucional a un juicio justo y para cumplir el rol de los tribunales como garantes de las libertades y derechos individuales.

La tarea principal del Tribunal Supremo, de conformidad con el art. 183.1 $\mathrm{CP}$, es la supervisión de las actividades de los tribunales ordinarios y militares en lo relativo a sus resoluciones. El objetivo de su actividad es garantizar el cumplimiento de la ley y la uniformidad de las sentencias de los tribunales ordinarios y militares. También desarrolla otras actividades especificadas en la Constitución y en las leyes (art. 183.2 CP). Entre las más importantes encontramos las siguientes: el conocimiento de los recursos electorales y la confirmación de la validez de las elecciones a la Cámara de Diputados, al Senado, la elección del Presidente de la República, las elecciones al Parlamento Europeo, el reconocimiento de las protestas contra la validez de un referéndum nacional y un referéndum constitucional y la confirmación de la validez de un referéndum. Además, opina sobre proyectos de ley y otros actos normativos, en la medida en que afecten a materias que son de la competencia del Tribunal Supremo. En el ámbito especificado en la ley, el Tribunal Supremo juzga también en los casos disciplinarios contra los jueces y otros funcionarios públicos, por ejemplo, fiscales, abogados, asesores legales y notarios.

Según el art. 179 CP, los jueces son nombrados por el Presidente de la República, a solicitud del Consejo Nacional de la Magistratura, por un período indefinido. Es una prerrogativa del Jefe del Estado, lo que significa que la validez de la ley de nombramiento no depende del refrendo del Primer Ministro (art. 144.2 y 3 CP). El Presidente sólo puede designar a un candidato presentado por el Consejo Nacional de la Magistratura. Las leyes sobre el sistema de determinados tipos de tribunales definen los requisitos para los candidatos a jueces, que deben garantizar un alto nivel de cualificaciones profesionales y morales.

3 Sentencias del TCP: de 15.01.2009, K 45/07, OTK-A 2009/1, pos. 3; de 14.10.2015, Kp 1/15, OTK-A 2015/9, pos. 147. 
El Consejo Nacional de la Magistratura es un órgano constitucional que, de conformidad con el art. 186.1 CP, custodia la independencia de los tribunales y la autonomía de los jueces. El Consejo Nacional de la Magistratura está integrado por: 1) el Primer Presidente del Tribunal Supremo, el Ministro de Justicia, el Presidente del Tribunal Supremo Administrativo y una persona designada por el Presidente de la República; 2) quince miembros elegidos entre los jueces del Tribunal Supremo, de los tribunales ordinarios, de los tribunales administrativos y de los tribunales militares; 3) cuatro miembros elegidos por la Cámara de Diputados, entre los diputados, y dos miembros elegidos por el Senado, entre los senadores. Se trata de una composición mixta, pues las tres autoridades están representadas en el Consejo, con predominio de representantes del poder judicial, lo que se justifica plenamente por la función constitucional del Consejo.

El Tribunal Constitucional es un órgano constitucional del Estado, independiente de los poderes legislativo y ejecutivo, y dentro del poder judicial tiene una posición separada frente a los tribunales, incluidos el Tribunal Supremo y el Tribunal Administrativo Supremo. El Tribunal Constitucional examina la conformidad de las leyes, los acuerdos internacionales, los reglamentos y las actividades de los partidos políticos con la Constitución. Las sentencias del Tribunal Constitucional son vinculantes y definitivas (art. 190.1 CP). El Tribunal Constitucional está integrado por quince jueces, elegidos una sola vez, por un período de nueve años. En el ejercicio de sus funciones, los jueces del Tribunal Constitucional son independientes y están sometidos únicamente a la Constitución (art. 195.1 CP). El Tribunal Constitucional desempeña también un papel importante en el sistema polaco de protección de los derechos humanos. A la luz de la Constitución, cada persona cuyos derechos o libertades constitucionales hayan sido violados, tiene derecho a presentar una denuncia ante el Tribunal Constitucional sobre la inconstitucionalidad de una ley u otro acto normativo, en virtud del cual un tribunal o un organismo de la administración pública dictó su sentencia (art. 79 CP).

\section{AMENAZAS AL PODER JUDICIAL}

La democracia es un concepto multifacético. Su dimensión básica se reduce a la soberanía de la nación, es decir, a las fuentes del poder, las formas de ejercerlo y los mecanismos para tener en cuenta la voluntad general en la creación de la política de Estado. Sin embargo, este enfoque solo incorpora una dimensión formal, y cuenta con el peligro de tener un carácter instrumental. Se expresa en un enfoque simplista de la democracia, basado en el gobierno de la mayoría. En el proceso de gobernar, los políticos reconocen que ganar las elecciones brinda una posibilidad ilimitada de moldear la realidad social. La preponderancia de los mecanismos formales provoca que los actores políticos desprecien el significado material de sus decisiones para justificar sus acciones como respuesta a la voluntad de la mayoría. La actividad política hace caso omiso de lo fundamental y se 
centra en la democracia procedimental. El fenómeno de constitutional hardball ${ }^{4}$ (juego duro) que se observa actualmente es consecuencia de la privación de sustancia de la democracia por parte de la mayoría política actual. La conciencia de este peligro requiere complementar el concepto de democracia con un aspecto material. La democracia es un conjunto de valores que sirven igualmente al individuo, a la sociedad y al Estado. Por ello, un Estado democrático es, en primer lugar, un Estado en el que la dignidad humana y los derechos y libertades están garantizados y protegidos. Los valores que también forman parte de la esencia de la democracia son la justicia social, la moralidad, la igualdad, el pluralismo, la seguridad y el orden público. Sin embargo, es imposible realizar estos valores sin la existencia de mecanismos que los garanticen, como la separación de poderes ${ }^{5}$, el Estado de Derecho y la independencia del poder judicial ${ }^{6}$.

Cada autoridad es responsable de observar el Derecho constitucional y de dar forma a la cultura constitucional. El poder legislativo cumple con esta obligación mediante la adopción de actos legales compatibles con la Constitución. El poder ejecutivo está obligado a observar la Ley Fundamental en todas las acciones que emprenda. Sin embargo, el funcionamiento de la democracia depende de manera especial del poder judicial. Los jueces, aparte del típico papel que se les asigna como intérpretes de la ley, también son mentores y educadores de la sociedad ${ }^{7}$. Ninguna autoridad es tan responsable de la conciencia jurídica como los jueces. La conciencia constitucional de los ciudadanos depende de que los jueces muestren valores constitucionales, expliquen su significado y transmitan este conocimiento a la sociedad. Este papel tan importante del juez en un Estado democrático se convierte en la razón de someter el poder político a los jueces. Los políticos contemplan a los jueces, no solo en el contexto de su función judicial, sino también de la educativa, como un corsé que limita sus acciones. Por ello, se esfuerzan por tener la mayor influencia posible en el contenido transmitido, tratando de reducir a los jueces al papel de propagadores de ideas necesarias para implementar la política actual. Por lo tanto, es una acción deliberada dirigida a crear los pensamientos y comportamientos sociales específicos. El poder político, si es que capta el significado de los valores, los capta en categorías particulares y de corto plazo. Sin embargo, los valores son universales y deberían resistir los intentos continuos de repudiarlos. Por lo tanto, el enfoque «educativo» del juez naturalmente va en contra de la política actual. Por lo tanto, solo un poder judicial independiente, que proteja la ley y los valores de las distorsiones, puede garantizar estos valores.

4 Tushnet, M., «Constitutional Hardball», John Marshall Law Review, n. ${ }^{\circ}$ 37, 2004, pp. 523 y ss.

5 Mőllers, CH., The Three Branches. A Comparative Model of Separation of Powers, Oxford University Press, Oxford, 2013, p. 47; Balazs, Z., The Principle of the Separation of Powers. A Defense, Lexington Books, London, 2016, pp. 31 y ss.

6 Barak, A., The Judge in a Democracy, Princeton University Press, Princeton \& Oxford, 2008, pp. 23-24.

7 Barak, A., The Judge..., op. cit., p. 23. 
El interés de los políticos hacia el poder judicial también se deriva del hecho de que el papel de esta autoridad en el país aumenta junto con la ampliación del ámbito sustantivo de los tribunales ${ }^{8}$. Debido al uso de las expresiones cada vez más imprecisas en los actos jurídicos y, también, debido a la inflación de la ley, el poder discrecional de los jueces está aumentando. El poder judicial a menudo juega un papel clave en la configuración de la política en los países democráticos, en la resolución de disputas políticas de importancia fundamental ${ }^{9}$, incluso los jueces toman decisiones que pueden afectar el resultado de las elecciones o al financiamiento de los partidos políticos con fondos públicos.

Los cambios iniciados en 2015 (en lo que respecta al Tribunal Constitucional) ${ }^{10}$ y en 2017-2019 (en lo que respecta al Tribunal Supremo, los tribunales ordinarios y el Consejo Nacional de la Magistratura) ${ }^{11}$ se acometieron con un objetivo claro: subordinar los titulares del poder judicial a los órganos políticos. La implementación de este objetivo siguió un esquema similar, sintéticamente formulado por L. Garlicki con las siguientes palabras: neutralización, absorción, sanación ${ }^{12}$. Las acciones políticas emprendidas contra el poder judicial consistieron, en primer lugar, en la introducción deliberada, por ley o mediante acciones reales, de perturbaciones en el buen funcionamiento de la institución, tales como los intentos estatutarios de destituir al Presidente del Tribunal Constitucional y el Primer Presidente del Tribunal Supremo, o la inhibición deliberada del proceso de nominación de los jueces por parte del Presidente de la República. Se necesitaba una parálisis institucional para preparar y aprobar proyectos de ley que permitirían realizar cambios de personal en los órganos judiciales. Esta segunda etapa fue la más prolongada, ya que requería modificar varias decenas de normas jurídicas, incluida la ley del Consejo Nacional de la Magistratura. Después de ganar influencia en la asignación de personal, la autoridad política eliminó apices iuris introducidos al principio, permitiendo así a los jueces y funcionarios

8 Guarnieri, C., Pederzoli, P., Thomas, C.A., The Power of Judges, Oxford University Press, Oxford, 2002, p. 6.

9 Smilov, D., The Judiciary: The Least Dangerous Branch, en M. Rosenfeld y A. Sajo (eds.), The Oxford Handbook of Comparative Constitutional Law, Oxford University Press, Oxford, 2012, p. 869.

10 Ley de 19 de noviembre de 2015 por la que se modifica la Ley del Tribunal Constitucional (Diario de Leyes de 2015 pos. 1928); Ley de 22 de diciembre de 2015 por la que se modifica la Ley del Tribunal Constitucional (Diario de Leyes de 2015 pos. 2217).

11 Ley de 8 de diciembre de 2017 del Tribunal Supremo (Diario de Leyes de 2018 pos. 5); Ley de 8 de diciembre de 2017 por la que se modifica la Ley del Consejo Nacional de la Magistratura y otras leyes (Diario de Leyes de 2018, pos. 3); Ley de 12 de abril de 2018 por la que se modifica la Ley del sistema de tribunales ordinarios, la Ley del Consejo Nacional de la Magistratura y la Ley del Tribunal Supremo (Diario de Leyes, pos. 848); Ley de 20 de diciembre de 2019 por la que se modifica la Ley sobre el sistema de tribunales ordinarios, la Ley del Tribunal Supremo y otras leyes (Diario de Leyes de 2020 pos.)

12 GARLICKI, L., Sądy polskie: neutralizacja, absorpcja, sanacja, una conferencia pronunciada el 2 de julio de 2020 en el seminario del Centro de Estudios Constitucionales Interdisciplinarios de la Facultad de Derecho y Administración de la Universidad Jaguelónica de Cracovia, https://cisk.wpia.uj.edu.pl/prof.-leszek-garlicki-sady-polskie-neutralizacja-absorpcja-sanacja-tekst-pierwszej-czesci-wykladu (acceso: el 30 de diciembre de 2020). 
judiciales recién nombrados utilizar las competencias de los órganos particulares de acuerdo con las expectativas políticas ${ }^{13}$. Es obvio, por tanto, que el retorno al funcionamiento de los órganos judiciales subordinados al poder político no fue resultado del deseo de eliminar los problemas antes mencionados, sino que tuvo como objetivo la utilización de la más amplia variedad de instrumentos por parte de un poder judicial más favorable a los políticos ${ }^{14}$.

\section{LOS CAMBIOS PERSONALES}

Evidentemente, era de una gran importancia ganar influencia en el nombramiento de jueces y presidentes de tribunales, del Tribunal Constitucional y del Consejo Nacional de la Magistratura. Tampoco es de extrañar que el Tribunal Constitucional se haya convertido en el primer órgano sujeto a tales cambios. Concretamente, se referían a tres jueces constitucionales, así como al presidente y al vicepresidente del Tribunal Constitucional.

De conformidad con el art. 194, ap. 1 CP, la Cámara de Diputados elige a los jueces del Tribunal Constitucional. En relación con las próximas elecciones parlamentarias, tanto los partidos mayoritarios de la Cámara de Diputados de la legislatura anterior, como los partidos con mayoría en la nueva legislatura, querían tener su influencia en la composición del Tribunal.

La Ley del Tribunal Constitucional aprobada en junio de 2015 fue una oportunidad para lograr esta influencia. Entró en vigor el 30 de agosto de 2015. Sobre esta base, la Cámara de Diputados de la séptima legislatura comenzó el proceso de selección de los jueces del Tribunal. El mandato de cinco jueces del Tribunal expiraba, respectivamente, el 6 de noviembre, el 2 y el 8 de diciembre de 2015 . La Cámara de Diputados de la séptima legislatura, en su sesión del 8 de octubre de 2015 seleccionó a los jueces para los cinco puestos. Como base legal para la selección utilizó el art. 137 de la Ley del Tribunal Constitucional, según el cual, en el caso de los jueces del Tribunal, cuyo mandato expiraba en 2015, el plazo para presentar un candidato a juez del Tribunal era de 30 días a partir de la fecha de entrada en vigor de la ley.

Las elecciones parlamentarias se celebraron el 25 de octubre de 2015 y el inicio del mandato de la nueva Cámara de Diputados comenzó el 12 de noviembre de 2015. Por lo tanto, según la cronología de acontecimientos, el mandato de tres jueces del Tribunal Constitucional expiró durante la séptima legislatura de la Cámara de Diputados y el de dos jueces después de la constitución de un nuevo Parlamento.

13 Pyziak-Szafnicka, M., «Trybunał Konstytucyjny á rebours», Państwo i Prawo, n. ${ }^{\circ}$ 5, 2020, pp. 25 y ss.

14 Matczak, M., «The Clash of Powers in Poland's Rule of Law Crisis: Tools of Attack and Self-Defense», Hague Journal on the Rule of Law, n. ${ }^{\circ}$ 12, 2020, pp. 421-450. 
La nueva Cámara de Diputados (octava legislatura), el 25 de noviembre de 2015, contrariamente a las disposiciones de la Constitución, ordenó que los jueces del Tribunal podían ser removidos de su cargo de oficio y adoptó una resolución «para determinar la ausencia de fuerza legal de las resoluciones de la Cámara de Diputados de la República de Polonia del 8 de octubre de 2015 sobre la elección de jueces del Tribunal Constitucional, publicadas en el Boletín Oficial del Estado el 23 Octubre de 2015 $»^{15}$. A continuación, el 2 de diciembre de 2015, la Cámara de Diputados eligió a cinco nuevos jueces del Tribunal Constitucional. Por la noche, ya el 3 de diciembre de 2015, el Presidente de la República tomó el juramento de cuatro personas elegidas para el Tribunal Constitucional el día anterior, y no permitió que los jueces elegidos por la Cámara de Diputados de la séptima legislatura presentaran su juramento.

Las actividades del 3 de diciembre de 2015 son de importancia clave para comprender la naturaleza de la crisis constitucional en Polonia. Este mismo día, en el Tribunal Constitucional, hubo una audiencia sobre la constitucionalidad del art. 137 de la Ley del Tribunal Constitucional, que sirvió de base para la elección de los 5 jueces por la Cámara de Diputados de la séptima legislatura. En su sentencia del 3 de diciembre de 2015 (K 34/15) ${ }^{16}$, el Tribunal consideró que el art. 137, con relación a los jueces del Tribunal cuyo mandato expiraba el 6 de noviembre de 2015, era de conformidad con el art. 194, ap. 1 CP; mientras que con relación a los jueces del Tribunal cuyo mandato expiraba, respectivamente, el 2 y el 8 de diciembre de 2015, era incompatible con el art. 194, ap. 1 CP. Dictaminó también que el Presidente de la República estaba obligado a tomar inmediatamente el juramento del juez del Tribunal elegido por la Cámara de Diputados. Los argumentos relativos al papel del Presidente se repitieron en la sentencia del Tribunal Constitucional de 9 de diciembre de 2015 (K 35/15) ${ }^{17}$. Se consideró que una situación en la que el Presidente, en virtud de la ley, podría bloquear la elección de un juez, realizada por la Cámara de Diputados de conformidad con la Constitución, debería ser considerada como un ejemplo de deterioro de la separación y equilibrio de poderes, y de la autonomía e independencia del poder judicial. A pesar de la decisión tan contundente del Tribunal Constitucional, el Presidente de la República nunca tomó el juramento de los tres jueces elegidos de conformidad con la Constitución. A su vez, el Presidente del Tribunal Constitucional se negó a aceptar a tres jueces elegidos para los puestos ya ocupados.

Como parte de su función directiva, el Presidente del Tribunal Constitucional no sólo influye en la autoridad de la corte constitucional, sino que también

15 Crisis similares ocurrieron en otros países de esta parte de Europa. Véase Dick Howard, A.E., Judicial Independence in Post-Communist Central and Eastern Europe, H. RusseL, D.M. O'Brien (eds.), Judicial Independence in the Age of Democracy. Critical Perspectives from around the World, University of Virginia Press, Virginia, 2001, pp. 96 y ss.

16 OTK ZU 11/A/2015, pos. 185.

17 OTK ZU 11/A/2015, pos. 186. 
tiene competencias organizativas importantes, en particular con respecto a la selección de un panel de jueces. El procedimiento de elección del Presidente y del Vicepresidente del Tribunal Constitucional, se encuentra regulado a nivel de la Constitución. Se indica en la misma que: «el Presidente y el Vicepresidente del Tribunal Constitucional serán nombrados por el Presidente de la República de Polonia entre los candidatos presentados por la Asamblea General de los Magistrados del Tribunal Constitucional» (art. 194.2), y las actas de nombramiento del Presidente y Vicepresidente del Tribunal Constitucional constituyen una prerrogativa presidencial (art. 144.3). La primera etapa de este procedimiento es la selección de candidatos por parte de la Asamblea General de los Magistrados del Tribunal Constitucional, y luego el Presidente de la República nombra al Presidente y Vicepresidente del Tribunal Constitucional de entre ellos.

La regulación constitucional del procedimiento de nominación deja un amplio margen de discrecionalidad al legislador, que fue utilizado por los diputados de Ley y Justicia en el segundo día del mandato del Parlamento recién elegido (el 13 de noviembre de 2015). Propusieron modificar la ley del Tribunal Constitucional. La norma fue adoptada 6 días después. Disponía que el mandato del actual Presidente y Vicepresidente del Tribunal expiraría tres meses después de la entrada en vigor de la ley (es decir, 14 días después). Esta disposición fue declarada inconstitucional por la sentencia del Tribunal Constitucional de 9 de diciembre de 2015, número $\mathrm{K} 35 / 15$.

Este intento infructuoso de cambiar los cargos gerenciales del Tribunal no desanimó a Ley y Justicia de presentar otra iniciativa legislativa al respecto ya en diciembre de 2015. Esta vez el cambio se refería al procedimiento de elección del Presidente y Vicepresidente del Tribunal Constitucional. El derecho de proponer a un candidato para el cargo de Presidente del Tribunal Constitucional se otorgó a grupos de tres jueces del Tribunal Constitucional ${ }^{18}$, mientras que cada juez del Tribunal Constitucional podía nominar a un solo candidato y votar por un solo candidato. Esta norma también fue objeto de revisión por parte del Tribunal, que, en su sentencia de 9 de marzo de 2016, número K 47/15, dictaminó la inconstitucionalidad de toda la norma, señalando que, a partir de la fecha de su publicación, todos los efectos jurídicos ocasionados por modificación legal se cancelarían. Esta fue la primera sentencia del Tribunal Constitucional cuya publicación fue rechazada por el Primer Ministro hasta el $2018^{19}$.

El tercer intento de cambiar el Presidente y Vicepresidente del Tribunal Constitucional consistió en la adopción, el 22 de julio de 2016, de una nueva ley sobre el Tribunal Constitucional, que introdujo nuevas reglas para la elección del Presidente y Vicepresidente del Tribunal Constitucional ${ }^{20}$. La Asamblea General

18 Esto no fue una coincidencia, ya que la Cámara de Diputados de la octava legislatura, quebrantando la Constitución, en diciembre de 2015 eligió a cinco jueces del Tribunal Constitucional.

19 Diario de Leyes del 5 de junio de 2018, pos. 1077.

20 Diario de Leyes pos. 1157. 
de Jueces del Tribunal Constitucional iba a presentar al Presidente de la República tres candidatos para el cargo de Presidente del Tribunal Constitucional (y, respectivamente, el Vicepresidente del Tribunal Constitucional). Cada juez del Tribunal Constitucional tenía derecho a proponer un candidato para este cargo, pero también a emitir un solo voto para el listado de todos los candidatos propuestos. Las disposiciones de esta ley también fueron revisadas por el Tribunal Constitucional, y en la sentencia de 7 de noviembre de 2016, número K 44/16 ${ }^{21}$, el Tribunal vinculó su constitucionalidad a una interpretación específica ${ }^{22}$. Esta sentencia fue, sin embargo, de poca importancia, ya que en noviembre de 2016 se aprobaron otras tres leyes relativas al Tribunal Constitucional. Su control por parte del Tribunal Constitucional resultó imposible, ya que entraron en vigor el 19 de diciembre de 2016, es decir, el último día del desempeño de su función por parte del Presidente del Tribunal Constitucional. Las normas contenidas en la ley permitieron nombrar como Presidente del Tribunal Constitucional a una persona ${ }^{23}$, a quien el líder del partido Ley y Justicia reconoció como su «descubrimiento social» ${ }^{24}$.

Contrariamente a las reglas anteriormente mencionadas, seis jueces elegidos por la Cámara de Diputados de la octava legislatura presentaron al Presidente de la República sus propios candidatos para el cargo del Presidente y el Vicepresidente del Tribunal Constitucional. Los otros jueces se negaron a participar en la Asamblea General. Aunque el candidato debe contar con el apoyo de la mayoría de los miembros de la Asamblea, el Presidente de la República nombró al nuevo Presidente del Tribunal Constitucional, elegido de entre los candidatos presentados.

Los cambios de personal con respecto al Tribunal Supremo incluyeron al Primer Presidente del Tribunal Supremo y a los jueces. Una forma de subordinar políticamente esta institución fue, en particular, rebajar la edad de jubilación de los jueces. A tal efecto, en diciembre de 2017 se aprobó una nueva ley sobre el Tribunal Supremo ${ }^{25}$.

De conformidad con la ley, los jueces pueden jubilarse con carácter general a los sesenta y cinco años (sesenta en el caso de las mujeres), a menos que declaren su voluntad de continuar en el ejercicio de sus funciones de forma previa (en el plazo de seis a doce meses previo) antes de alcanzar esta edad. La decisión sobre si un juez particular podrá continuar trabajando pertenece al Presidente de la

21 La publicación de esta sentencia se retrasó dos años.

22 Chmielarz-Grochal, A., Laskowska, M., SuŁkowski, J., «La crisis constitucional en Polonia (sobre la oportunidad perdida de solucionarla). Un estudio de caso», RGDC n. ${ }^{\circ} 27,2018$, pp. 37 y ss.

23 En vista del método de nombrar a J. Przyłębska para el cargo de Presidenta del Tribunal Constitucional, surgieron numerosas dudas, más ampliamente, en el acta de la Asamblea General de Jueces del Tribunal Constitucional del 20 de diciembre de 2016, http://www.hfhr.pl/wp-content/uploads/2017/01/ protokol-obrad-Zgromadzenia-Ogolnego-STK-w-dniu-20-XII-2016-r.pdf (acceso: 30/122020).

24 Véase: https://www.polsatnews.pl/wiadomosc/2019-06-28/mucha-odkrycie-towarzyskie-czyli-pani-przylebska-wydaje-takie-orzeczenia-jakie-sobie-zyczy-pis/ (acceso: 30/12/2020).

25 Ley de 8 de diciembre de 2017 del Tribunal Supremo. 
República, que puede consultar en este caso al Consejo Nacional de la Magistratura (art. 37.1). El consentimiento se otorga por un período de tres años y, como máximo, por dos veces. De acuerdo con el art. 111 de la nueva Ley, todos los jueces que hayan cumplido sesenta y cinco años deberán retirarse. Todos los jueces tendrán que presentar la declaración sobre su voluntad de continuar trabajando, en el primer mes tras la entrada en vigor de la ley. Esto también se aplicará al actual Primer Presidente del Tribunal Supremo. Las soluciones introducidas fueron cuestionadas por la Comisión Europea, que presentó una denuncia contra Polonia de conformidad con el art. 258 del Tratado de Funcionamiento de la Unión Europea. El TJUE, por resolución de 17 de diciembre de 2018, en el asunto C-619/18 $\mathrm{R}^{26}$, suspendió la aplicación de la normativa controvertida. Polonia formalmente cumplió con esta resolución. En enero de 2019 entró en vigor la ley que habilitaba el retorno a los cargos, pero un gran número de jueces no se aprovechó de esta opción ${ }^{27}$. Finalmente, en la sentencia de 19 de junio de 2019, en el asunto C-619/18, el TJUE resolvió que «La República de Polonia ha incumplido las obligaciones que le incumben en virtud del art. 19 del TUE, ap. 1, párrafo 2, al prever, por un lado, la aplicación de la medida de reducción de la edad de jubilación de los jueces del Tribunal Supremo a los jueces de ese Tribunal en ejercicio nombrados con anterioridad al 3 de abril de 2018, y al atribuir, por otro lado, al Presidente de la República la facultad discrecional para prorrogar la función jurisdiccional en activo de los jueces de dicho Tribunal una vez alcanzada la nueva edad de jubilación ${ }^{28}$.

Es difícil suponer que el promotor del proyecto de la ley no fuese consciente, considerando la edad del entonces Primer Presidente del Tribunal Supremo, de que la introducción de una disposición que especificara una edad límite de la jubilación de los jueces implicaría también la necesidad de elegir a un nuevo juez para esta función. La ley contenía una disposición transitoria, según la cual, hasta que no se eligiera a un nuevo Primer Presidente del Tribunal Supremo, el Presidente de la República encomendaría la dirección del Tribunal Supremo a un magistrado designado por él. Esta solución constituía indudablemente otra violación de la Constitución.

De acuerdo con el art. 183, ap. 3 CP, el Primer Presidente del Tribunal Supremo es nombrado por un período de seis años. Este plazo es una de las garantías de independencia de este órgano y del Tribunal. Además, el Primer Presidente es un miembro del Consejo Nacional de Magistratura y preside el Tribunal de Estado. Por lo tanto, la interrupción de su mandato es constitucionalmente inaceptable y contraria al principio constitucional de continuidad del poder estatal. La Ley Fundamental tampoco permite que cualquiera pueda ejercer los cargos ejecutivos del Tribunal

26 ECLI:EU:C:2018:1021.

27 Ley de 21 de noviembre de 2018 del Tribunal Supremo.

28 ECLI:EU:C:2019:531. 
Supremo, salvo el Primer Presidente y los otros presidentes de este Tribunal. Por lo tanto, es constitucionalmente inaceptable encomendar la dirección del Tribunal Supremo a un juez designado por el Presidente de la República.

No son las únicas objeciones en contra de la ley mencionada. La elección de un nuevo Primer Presidente del Tribunal Supremo requiere la presentación al Jefe del Estado de los candidatos por la Asamblea General del Tribunal Supremo. Sin embargo, el cumplimiento de esta obligación dependerá de los cambios personales en la composición del Tribunal. El requisito previo para empezar el procedimiento de selección fue completar los 110 puestos de magistrados en el Tribunal Supremo. De esta manera, el legislador estuvo prolongando el tiempo necesario para la elección del Primer Presidente del Tribunal Supremo. La intención del legislador parece ser obvia: eliminar al Primer Presidente, situar temporalmente en este cargo a una persona indicada por el Presidente de la República y, después de efectuar cambios personales en el Tribunal, elegir a un nuevo Primer Presidente.

Gracias a la intervención del TJUE, el Primer Presidente del Tribunal Supremo ocupó el cargo hasta el final de su mandato de 6 años (abril de 2020). Sin embargo, la manipulación legislativa llevó a que los jueces minoritarios elegidos para el Tribunal Supremo a partir de 2018 propusieran a uno de los candidatos a Primer Presidente del Tribunal Supremo. En 2020, el Presidente nombró a un candidato que no contó con el apoyo de la mayoría de los jueces.

El análisis de la ley no permite identificar un propósito constitucional o valores que legitimaran unos cambios tan profundos. Tampoco se trata de una evaluación negativa de la política de eliminación de huellas de comunismo en el ambiente judicial. En primer lugar, tal evaluación entra en la esfera política y no la legal. En segundo lugar, incluso suponiendo que una parte de la comunidad judicial del Tribunal Supremo cooperara con las autoridades de la República Popular, el instrumento legal para verificar este entorno no puede ser el apartamiento de un grupo de jueces sin una evaluación individual de la conducta de cada uno de ellos. Por encima de todo, esas razones para el cambio aducidas en la exposición de motivos del proyecto de la ley son ilógicas. La ley entró en vigor en abril de 2018, por tanto, la edad de 65 años sería alcanzada por personas nacidas en 1953 (y en el caso los jueces que recibiesen el consentimiento de continuar trabajando, en 1948). Estos jueces, considerando que para ocupar el cargo de un juez del Tribunal Supremo existía el requisito de tener al menos 10 años de experiencia profesional, no pudieron comenzar a desempeñar sus funciones antes de 1989. La inadecuación del criterio de eliminación de huellas de comunismo es aún más clara si se tiene en cuenta que la ley prevé una vacatio legis de tres meses y un período de jubilación de tres meses, a partir de la fecha de entrada en vigor de la ley. Por lo tanto, el legislador excluye a los jueces de la actividad profesional que comenzaron a desempeñar medio año después.

La falta de proporcionalidad de las nuevas regulaciones es obvia y deriva de la falta de un propósito que justifique un cambio tan profundo en la composición 
del Tribunal Supremo. El legislador omite por completo que, al introducir los cambios propuestos, se desvía del principio de inamovilidad del juez y utiliza dos excepciones constitucionales al mismo tiempo (dos motivos para reorganizar el trabajo del Tribunal Supremo a los cuales se refieren los aps. 4 y 5 del art. 180). Desde el punto de vista de la regla de inamovilidad del juez, el uso de dos excepciones a la misma requiere una justificación aún más convincente, y esto es lo que falta. En segundo lugar, existe una alta probabilidad de interrupciones importantes en el funcionamiento del Tribunal Supremo, ya que de repente casi un $40 \%$ de los jueces se jubilarán, mientras que se incorporarán docenas de nuevos jueces.

Pero el legislador no se detuvo en la sustitución de los jueces del Tribunal Supremo. Los cambios de personal también se realizaron en los órganos directivos de los tribunales ordinarios. En 2017 entró en vigor la ley que consolidó la posición del Ministro de Justicia en cuanto a sus competencias en materia de nombramientos. El nuevo procedimiento de nombramiento y destitución de los presidentes y vicepresidentes de tribunales ordinarios plantea dudas muy importantes. La competencia en materia de nombramientos ha sido formulada de tal manera que permite al Ministro interferir de manera completamente arbitraria en el poder judicial. En principio, los cambios fueron motivados por la voluntad política de reemplazar al personal en puestos directivos en los tribunales. El legislador volvió a regular los motivos para destituir al presidente (vicepresidente) durante su mandato: incumplimiento persistente de los deberes oficiales y, particularmente, baja eficiencia de las actividades en el ámbito de la supervisión administrativa o de la organización del trabajo en un tribunal o en tribunales inferiores. Estas premisas tienen carácter de cláusulas generales. Por lo tanto, pueden conducir a que el Ministro de Justicia adopte decisiones de despido, lo que supondría una injerencia desproporcionada en el ejercicio del poder judicial. Si bien el Consejo Nacional de la Magistratura puede emitir una opinión negativa sobre la intención de destituir al presidente o vicepresidente de un tribunal, solo es vinculante en caso de que se adopte una resolución sobre este asunto por mayoría cualificada de $2 / 3$ votos. Sin embargo, debido a que, de acuerdo con la Ley del Consejo Nacional de la Magistratura, la elección de los jueces que integran el Consejo la realiza la Cámara de Diputados, se puede concluir que la resolución adoptada por el Consejo sobre la legitimidad de la destitución del presidente no es una garantía suficiente para asegurar la independencia del poder judicial en este aspecto.

Sin embargo, los cambios introducidos eran de poca importancia, ya que las nuevas disposiciones estipulaban que el Ministro de Justicia podía destituir a los presidentes (vicepresidentes) de los tribunales en un plazo de 6 meses sin ninguna justificación y sin consultar a los colegios de los tribunales particulares ${ }^{29}$. En el

29 Se realizaron cambios similares en la República Checa, véase Kosař, D., «Politics of Judicial Independence and Judicial Accountability in Czechia: Bargaining in the Shadow of the Law between Court Presidents and the Ministry of Justice», European Constitutional Law Review, n. ${ }^{\circ}$ 13, 2017, pp. 96-123. 
período del 12 de agosto de 2017 al 12 de febrero de 2018, 158 personas fueron despedidas, principalmente en las grandes ciudades, donde están en curso los procesos que pueden despertar el interés de los políticos. Al mismo tiempo, el Ministro nombró 229 nuevos presidentes y vicepresidentes de tribunales ordinarios. Los cambios de personal afectaron a la mitad de los tribunales de apelación y de los tribunales de distrito ${ }^{30}$.

Los cambios de personal, que violaban la independencia constitucional del poder judicial, afectaron también a los jueces de los tribunales ordinarios. El legislador rebajó la edad de jubilación de los jueces de los tribunales ordinarios, la diferenció según el sexo y otorgó al Ministro de Justicia un derecho para decidir sobre la edad de jubilación de los jueces. A raíz de otra denuncia de la Comisión Europea, el Tribunal de Justicia dictó una sentencia el 5 de noviembre de 2019, en el asunto C-192/18 ${ }^{31}$, en la que resolvió que al establecer las disposiciones sobre la edad de jubilación en la forma impugnada, Polonia violó el Derecho de la Unión Europea.

\section{LOS CAMBIOS SISTÉMICOS Y DE ORGANIZACIÓN}

Numerosos cambios de personal fueron acompañados por transformaciones políticas y organizativas. Los cambios en la organización y competencias del Tribunal Supremo fueron de gran importancia.

El interés de los gobernantes por el Tribunal Supremo tiene que ver con la posición del mismo, que, de conformidad con el art. 183.3 CP, ejerce las competencias que le encomienda la ley. La autoridad política utilizó las leyes para imprimir un nuevo carácter a las tareas del Tribunal. Más importante aún, la Constitución no limita al legislador en cuanto al diseño de la estructura interna del Tribunal Supremo y, por lo tanto, dicha institución ha sido completamente reorganizada.

Para la implementación de nuevas funciones se establecieron dos nuevas cámaras del Tribunal Supremo: la Cámara de Control Extraordinario y Asuntos Públicos y la Cámara Disciplinaria. La Cámara de Control Extraordinario y Asuntos Públicos se encargó principalmente de examinar las quejas extraordinarias, decidir sobre la validez de las elecciones y controlar las finanzas de los partidos políticos. La Cámara Disciplinaria, por su función, tiene un estatus especial entre las cámaras del Tribunal Supremo, para que pueda realizar tareas de las cuales depende en gran medida el nivel de confianza de los ciudadanos en el poder judicial. La Cámara Civil, la Cámara Penal y la Cámara de Trabajo y Seguridad Social siguen funcionando en el Tribunal Supremo. Estas cámaras están compuestas por los jueces

30 Véase el informe detallado sobre el intercambio de jueces publicado por la Asociación de Jueces Polacos «Iustitia», https://www.iustitia.pl/informacja-publiczna/2223-czystki-kadrowe-w-sadach-ad-2018-ujawniamy-pelne-zestawienie (acceso: 11/01/2021).

31 ECLI:EU:C:2019:924. 
recién elegidos. Al mismo tiempo, está en marcha la contratación de nuevos jueces en las cámaras restantes. Actualmente, de los 97 jueces del Tribunal Supremo, 46 jueces (es decir, un 47\%) han sido nombrados según el nuevo reglamento.

En 2018, por primera vez en los 100 años de historia del Tribunal Supremo, se le encomendó al Presidente la facultad de emitir el reglamento interno del Tribunal Supremo. De conformidad con la ley, el Presidente de la República de Polonia determinó el reglamento del Tribunal Supremo, en el que definió el número de cargos de jueces del Tribunal Supremo (al menos 120), incluyendo su número en cámaras particulares, la organización interna del Tribunal Supremo, así como el alcance y la forma de realizar las actividades de los asistentes de jueces, teniendo en cuenta la necesidad de asegurar el funcionamiento eficiente del Tribunal Supremo, sus cámaras y órganos, la especificidad de los procedimientos ante él, incluidos los procedimientos disciplinarios, y el número y tipo de casos examinados. La regulación tiene origen en una ley que no puede regular estos asuntos. Por regla general, la Constitución encomienda a los órganos ejecutivos la emisión de actos ejecutivos. Esta solución es coherente con el principio de separación de poderes, ya que los órganos encargados de aplicar las leyes tienen un conocimiento más profundo y especializado de las áreas individuales de la política estatal, y debido a la proximidad de estas entidades a departamentos específicos de la administración gubernamental, es una regla general dotar a los ministros, al Primer Ministro o al Consejo de Ministros de competencias para dictar regulaciones. La presencia del ejecutivo en la política actual de Estado es al mismo tiempo un argumento que excluye la imposición de normas internas a los órganos constitucionalmente independientes. Esta tesis se ve reforzada por la necesidad de obtener una firma mancomunada del Primer Ministro y el Jefe de Estado. La influencia de otro órgano ejecutivo multiplica el peligro sistémico de la influencia política en la organización interna del Tribunal Supremo.

\section{LA POLITIZACIÓN DEL PROCESO DE NOMBRAMIENTO DE LOS JUECES}

El proceso de nombramiento de los jueces fue subordinado a los objetivos políticos. Tomar el control de este procedimiento requirió el uso de dos mecanismos.

En primer lugar, se pretendió eliminar la revisión judicial independiente de las resoluciones del Consejo Nacional de la Magistratura. Por lo tanto, se introdujo la posibilidad de apelación de los jueces de tribunales ordinarios a la recién creada Cámara de Control Extraordinario y Asuntos Públicos. Por las mismas razones, los candidatos a jueces del Tribunal Supremo fueron privados de este derecho ${ }^{32}$. Las

32 Asunto C-824/18, http://curia.europa.eu/juris/document/document.jsf?text=\&docid=213969\&pageIndex $=0 \&$ doclang $=E S \&$ mode $=1$ st $\&$ dir $=\& o c c=$ first $\&$ part $=1 \&$ cid $=4072064$ (acceso: el 11 de enero de 2021). Luego, para evitar el discurso del TJUE, se derogaron las disposiciones nacionales en cuestión. 
disposiciones establecían que un candidato a magistrado del Tribunal Supremo tenía derecho a apelar ante el Tribunal Supremo Administrativo. Por temor a que el Tribunal Supremo Administrativo emita el fallo, el legislador paralizó inicialmente el procedimiento de apelación (adoptó dos actos modificativos). En relación con su adopción, el Tribunal Supremo Administrativo que examina los recursos remitió cuestiones prejudiciales al TJUE.

El Tribunal de Justicia de la Unión Europea en la sentencia del 2 de marzo de 2021 (C-824/18) falló que las enmiendas a la Ley del Consejo Nacional del Poder Judicial, que llevaron a la abolición del control judicial efectivo de las decisiones del Consejo sobre la presentación al Presidente de la República de solicitudes de nombramiento de los candidatos a magistrados del Tribunal Supremo, puede violar el derecho de la Unión Europea. Al mismo tiempo, el Tribunal declaró que si el órgano jurisdiccional nacional llega a la conclusión de que las modificaciones legislativas de 2018 infringen el derecho de la UE, se le exigirá, de conformidad con el principio de primacía de dicha ley, apartarse de dichas modificaciones en favor de la aplicación ${ }^{33}$. Esta sentencia permite al Tribunal Supremo Administrativo revisar los recursos de los candidatos rechazados por el Consejo en el proceso de calificación para los cargos de magistrados del Tribunal Supremo. La Comisión Europea ha anunciado que supervisará la ejecución de la sentencia.

En segundo lugar, debido al papel clave del Consejo Nacional de la Magistratura en este procedimiento, se realizaron cambios en el procedimiento de selección de los jueces miembros del Consejo. La reforma supone que la selección sea realizada por la Cámara de Diputados por mayoría cualificada de 3/5 de votos en presencia de al menos la mitad del número estatutario de diputados, para un mandato conjunto de cuatro años, incluida la necesidad de una representación en el Consejo de jueces de diversos tipos y niveles de las cortes. Para presentar candidatos a los miembros del Consejo están autorizados: un grupo de al menos dos mil ciudadanos de la República y un grupo de al menos 25 jueces. De entre los candidatos propuestos, los grupos parlamentarios presentan a la Comisión de Justicia y Derechos Humanos de la Cámara de Diputados los nombres de los candidatos recomendados, y solo sobre esta base se crea una lista final de 15 candidatos para los miembros del Consejo Nacional de Magistratura. La elección requiere, por tanto, un acuerdo entre los grupos políticos representados en la Cámara de Diputados y, en su ausencia, la Cámara de Diputados elegirá a los miembros del Consejo por mayoría absoluta de votos.

La pregunta clave se limita a confirmar si es aceptable, desde el punto de vista de la Constitución de Polonia, confiar la competencia para la elección a la Cámara de Diputados, dentro del ámbito propuesto por el Presidente. La respuesta a tal pregunta debe ser inequívocamente negativa debido al contenido del art. $187 \mathrm{CP}$

33 ECLI:EU:C:2021:153. 
sobre la composición del Consejo Nacional de la Magistratura ${ }^{34}$, el papel del Consejo como guardián de la independencia de las cortes y la autonomía de los jueces (art. $186 \mathrm{CP}^{35}$ ), y también, en el contexto constitucional más amplio, la dominación del factor judicial en la creación de las entidades del poder judicial.

La Constitución proporciona argumentos que claramente excluyen la posibilidad de elección de los jueces miembros del Consejo Nacional de la Magistratura por la Cámara de Diputados. El Consejo se compone de varias categorías de miembros. En el primer grupo, se encuentran el Primer Presidente del Tribunal Supremo, el Ministro de Justicia, el Presidente del Tribunal Supremo Administrativo y una persona designada para el Consejo por el Presidente de la República; en el segundo, 15 jueces de las cortes de diversos niveles; y, en el tercero, miembros del Parlamento, incluidos cuatro diputados elegidos por la Cámara de Diputados y dos senadores elegidos por el Senado.

La Constitución define exhaustivamente el alcance subjetivo de la función de nombramiento de la Cámara de Diputados con respecto al Consejo Nacional de la Magistratura (art. 187.1). Debe estipularse que tanto el poder ejecutivo como el legislativo tienen una influencia exclusiva en la selección de sus propios representantes en el Consejo. No es un recurso casual, el Consejo Nacional de la Magistratura siempre ha sido percibido como un ejemplo institucional del funcionamiento del principio de la separación de poderes. Debido al papel político del Consejo, el poder judicial debería tener el mayor impacto en la composición personal de este órgano.

La interpretación teleológica de las disposiciones de la Constitución sobre el Consejo Nacional de la Magistratura lleva a las mismas conclusiones. El art. 186 define este órgano como el guardián de la independencia de las cortes y la autonomía de los jueces, equipando el Consejo con competencias específicas para su protección. Por lo tanto, el art. 187, ap. 1, párrafo 2, debe entenderse desde la perspectiva de esta función. Una condición imprescindible para proteger la independencia de las cortes y la autonomía de los jueces es equipar al guardián de estos valores con su propia calidad de independencia. El hecho de excluir (o

34 Art. 187: 1. El Consejo Nacional de Magistratura se compone de: 1) El Primer Presidente del Tribunal Supremo, el Ministro de Justicia, el Presidente del Tribunal Supremo Administrativo, y una persona designada por el Presidente de la República. 2) Quince miembros elegidos entre los jueces y magistrados del Tribunal Supremo, de las cortes ordinarias, de las cortes de lo contencioso-administrativo y de las cortes militares. 3) Cuatro miembros elegidos por la Cámara de Diputados entre sus miembros, y dos miembros elegidos por el Senado entre los senadores. 2. El Consejo Nacional de Magistratura elegirá, entre sus miembros, a su presidente y a dos vicepresidentes. 3. La duración del mandato de los elegidos como miembros del Consejo Nacional de Magistratura es de cuatro años. 4. La organización, el ámbito competencial y el modo de funcionamiento del Consejo Nacional de Magistratura, así como el modo de elección de sus miembros, serán determinados por la ley.

35 Art. 186: 1. El Consejo Nacional de Magistratura custodia la independencia de las cortes y la autonomía de los jueces. 2. El Consejo Nacional de Magistratura puede plantear cuestiones al Tribunal Constitucional acerca de la constitucionalidad de los actos normativos en la medida en que éstos conciernan a la independencia de las cortes y a la autonomía de los jueces. 
incluso minimizar) la influencia del poder judicial sobre la elección de los miembros del Consejo y confiar esta competencia a la Cámara de Diputados puede llevar a una preocupación justificada sobre la participación del poder judicial y el propio Consejo Nacional en la política actual y socavar su autoridad como órgano independiente. Además, el cambio propuesto es un ejemplo de una seria perturbación del mecanismo de cooperación entre varios segmentos de poder. El Consejo Nacional fue concebido constitucionalmente como una plataforma de cooperación de los poderes legislativo, ejecutivo y judicial, con el fin de proteger la independencia de las cortes y la autonomía de los jueces. La representación de las tres autoridades no puede tratarse nominalmente. No se trata de la propia pertenencia de los miembros del Consejo a las autoridades particulares (diputado como representante del poder legislativo, juez como representante del poder judicial), sino de la influencia real de estas autoridades en la selección de sus propios representantes. Limitar la interpretación de la Constitución al aspecto semántico permitiría un razonamiento ad absurdum. Si no tiene importancia quién elige a los miembros del Consejo, se podría suponer que los jueces seleccionarían a los diputados, los diputados a los ejecutivos y los representantes del poder ejecutivo a los diputados. Por tanto, la pregunta a plantearse sería, a quién representan los miembros individuales del Consejo, a las entidades que les eligen, o a su propio entorno profesional.

Desde este punto de vista, debe señalarse que el art. 186 proporciona al legislador una pista sobre el contenido de las disposiciones que concretan el procedimiento para seleccionar a los miembros del Consejo.

La interpretación sistemática de la Constitución también indica que la Cámara de Diputados no debería tener un impacto tan profundo en la composición personal del Consejo Nacional de la Magistratura. Aunque el Consejo no es un órgano perteneciente al poder judicial, es este segmento de poder con el que está más estrechamente relacionado. Por lo tanto, es posible y necesario ver la composición personal del Consejo en el contexto constitucional más amplio, en relación con las competencias en materia de personal en el ámbito del poder judicial. La Constitución concede al Presidente una prerrogativa para nombrar el Primer Presidente del Tribunal Supremo, el Presidente del Tribunal Supremo Administrativo, el Presidente y el Vicepresidente del Tribunal Constitucional, pero la condiciona por la decisión de los propios jueces con respecto a presentar sus candidaturas para estos puestos. Son las asambleas generales de los jueces de estos tribunales las que tienen el derecho exclusivo de presentarlas. También la práctica actual de nombramiento de los jueces confirma que la elección de un juez es una decisión que está influenciada principalmente por el entorno judicial. En otras palabras, de la perspectiva de la Constitución es imposible indicar casos en los que el poder judicial esté privado de su influencia sobre la composición personal de un órgano de este poder.

Un argumento que abona la tesis sobre la inadmisibilidad de los cambios propuestos es el comparativo. De los 23 Estados miembros de la UE con consejos 
judiciales a nivel nacional, en 18 países los representantes del poder judicial constituyen una mayoría del Consejo o tienen en él un voto decisivo. En dos países de la UE, los jueces forman exactamente la mitad de los miembros del Consejo, y en tres otros países de la UE los jueces constituyen una minoría en el Consejo. Además, en 18 países los miembros del Consejo son elegidos por otros jueces, o la mayoría de los miembros son representantes de la judicatura que forman parte del Consejo de oficio. En dos países donde hay dos órganos que realizan las funciones del Consejo de Magistratura (Hungría y Suecia), en uno de ellos los miembros son elegidos por los jueces. Solo en tres países de la Unión Europea los jueces son designados por los órganos ejecutivos o legislativos, aunque en España, para los vocales de origen judicial, son las asociaciones judiciales o veinticinco jueces o magistrados los que realizaran las propuestas sobre las que deberán decidir las Cortes Generales, y en los otros dos casos el Ministro de Justicia es formalmente (Dinamarca) o de hecho (los Países Bajos) obligado por las recomendaciones de los representantes del poder judicial ${ }^{36}$.

Además, lo previsto en la enmienda «democratización» del procedimiento de la elección de los miembros del Consejo Nacional de la Magistratura y su elección por la Cámara de Diputados de entre los candidatos nominados no solo por un grupo de jueces, sino también por los ciudadanos, puede en la práctica debilitar el órgano que custodia la independencia de las cortes y la autonomía de los jueces, y subordinarlo al poder legislativo. Teniendo en cuenta también la terminación anticipada del mandato actual de los miembros del Consejo, debe señalarse que las disposiciones previstas en la ley provocan una injerencia importante en el principio de independencia y autonomía del poder judicial que, a su vez, es una garantía del principio de la separación de poderes (art. 10 en relación con el art. $173 \mathrm{CP})$.

En cuanto al alcance constitucionalmente aceptable de los cambios en el Consejo Nacional de la Magistratura, la Constitución define las bases de su organización y funcionamiento, y el art. 187.1 no puede ser interpretado de otra manera que desde la perspectiva de una competencia nominativa reservada para las autoridades judiciales. Si el Consejo fue constituido como una ejemplificación del principio de la separación de poderes, y el legislador constitucional aseguró a todos los poderes su participación en la creación de esta institución, pretender derivar del art. 187 motivos para confiar a la Cámara de Diputados (fuera del alcance mencionado explícitamente en el ap. 1, párrafo 3) una competencia para nombrar a los jueces del Consejo, debe considerarse como una interpretación contra legem.

Los cambios de personal del Consejo Nacional de la Magistratura suscitaron más dudas en cuanto a las juntas de adjudicación en casos individuales examinados por los tribunales. A raíz de la sentencia del TJUE, que definió los criterios

36 Borkowski, G., MichalcZewski, R., «Skład i sposób wyboru sędziów do rad sądownictwa w krajach członkowskich Unii Europejskiej», Krajowa Rada Sąownictwa. Kwartalnik, n. ${ }^{\circ}$ 2, 2017, pp. $45-46$. 
para evaluar un tribunal independiente ${ }^{37}$, se cuestionó la condición de un juez designado sobre la base de la recomendación del Consejo Nacional de la Magistratura, constituido inconstitucionalmente ${ }^{38}$. Como resultado de esta sentencia, el Tribunal Supremo, integrado por las Cámaras Civil, Penal y de Trabajo y Seguridad Social, el 23 de enero de 2020, adoptó la resolución n. ${ }^{\circ}$ BSA I-4110$1 / 2020$, en la que manifestó que la participación en la composición del juzgado de una persona designada para el cargo de juez por la solicitud del Consejo Nacional de la Magistratura designado según el nuevo procedimiento, viola la Constitución y la Convención sobre la Protección de los Derechos, las libertades fundamentales y la Carta de los Derechos Fundamentales de la UE ${ }^{39}$. A pesar del carácter innovador de esta resolución, el problema de la composición del tribunal raramente ocurre en la práctica. Además, el Tribunal Constitucional notó en esta resolución un intento de interferir por parte del Tribunal Supremo en las actividades legislativas y dictaminó el 28 de abril de 2020 que el Tribunal Supremo no tenía competencia para interpretar disposiciones legales que condujeran a un cambio en el estatus normativo del ámbito del sistema y organización del poder judicial $^{40}$.

\section{UN NUEVO RÉGIMEN DISCIPLINARIO}

Otra amenaza real para la independencia judicial es un sistema revolucionario de responsabilidad disciplinaria de los jueces. Se basa en dos divisiones organizativas de nueva creación. La primera de ellas está formada por agentes disciplinarios que actúan como fiscales. Funcionan en varios niveles del poder judicial (a nivel de los tribunales de distrito, de los tribunales de apelación y del Tribunal Supremo), sin embargo, el sistema está altamente centralizado y subordinado al Fiscal Disciplinario de los Jueces de los Tribunales Ordinarios designado por el Ministro de Justicia. Independientemente de esto, el Ministro de Justicia puede nombrar al Fiscal Disciplinario del Ministro de Justicia para que lleve a cabo un caso específico relacionado con un juez, lo que excluye a otro fiscal de actuar en el caso. A

37 En la Sentencia del Tribunal de Justicia (Gran Sala) de 19 de noviembre de 2019 (peticiones de decisión prejudicial planteadas por el Sąd Najwyższy — Polonia) — A. K. / Krajowa Rada Sądownictwa (C-585/18) y CP (C-624/18), DO (C-625/18) / Sąd Najwyższy (Asuntos acumulados C-585/18, C-624/18 y C-625/18) el TJUE dictaminó que al evaluar la independencia de un tribunal, es necesario tener en cuenta «las circunstancias objetivas en las que se estableció un determinado organismo y sus características, así como el método de nombramiento de sus miembros», ECLI:EU:C:2019:982.

38 Sin embargo, cabe señalar que el Tribunal Constitucional, en su sentencia de 25 de marzo de 2019, consideró que la modificación a la Ley del Consejo Nacional de la Magistratura era compatible con la Constitución. El relator fue el así llamado juez doble, que ingresó al asiento ya ocupado, y los miembros restantes del panel de jueces fueron nominados por el partido Ley y Justicia. Caso K 12/18, OTK ZU A/2019, pos. 17.

39 Véase http://www.sn.pl/aktualnosci/SiteAssets/Lists/Wydarzenia/AllItems/BSA\%20I-4110-1_20_ English.pdf (acceso: 11/01/2021).

40 Auto del TCP no. Kpt 1/20 de 21 de abril de 2020 (OTK ZU A/2020, pos. 60). 
solicitud del Ministro de Justicia, los fiscales inician procedimientos disciplinarios. Este sistema, sin embargo, no garantiza ninguna independencia política. La segunda división organizativa consta de tribunales disciplinarios separados, establecidos en 2018. Resuelven la mayoría de los casos disciplinarios de los jueces en primera instancia, salvo los delitos más graves, para los que es competente la Cámara Disciplinaria del Tribunal Supremo. La Cámara, al mismo tiempo, es un tribunal de apelación para los casos disciplinarios de los jueces.

Como resultado de esta modificación, el Ministro de Justicia, además de los poderes creativos antes mencionados, ganó plena influencia en el curso del proceso disciplinario. Tiene competencia para presentar una solicitud al fiscal para iniciar un procedimiento y para apelar contra la decisión del fiscal, si el mismo ha suspendido el caso iniciado por el Ministro. Además, si el fiscal dicta la decisión de no iniciar un procedimiento, el Ministro de Justicia puede presentar una objeción, lo que equivale a la obligación de iniciar un procedimiento disciplinario. Las indicaciones del Ministro de Justicia sobre el curso posterior del procedimiento son vinculantes para el fiscal.

Asimismo, no deja de ser significativo que el catálogo de las sanciones disciplinarias se haya ampliado: las nuevas sanciones consisten en una reducción de la remuneración o la imposición de una multa al juez.

Los cambios introducidos son un ejemplo flagrante del uso del sistema disciplinario con fines políticos. Actualmente, numerosas sanciones contra los jueces tienen como objetivo atemorizarlos y desincentivarles de juzgar las actuaciones de las autoridades políticas. Por este motivo, el Tribunal de Justicia de la UE reconoce una denuncia presentada por la Comisión Europea contra Polonia en octubre de 2019, relativa a las disposiciones sobre procedimientos disciplinarios contra jueces (asunto C-791/19) ${ }^{41}$. Aunque el Tribunal, en la sentencia de 8 de abril de 2020, asunto C-791/19 R, decidió aplicar medidas cautelares en forma de suspensión de las actividades de la Cámara Disciplinaria del Tribunal Supremo ${ }^{42}$, Polonia hizo caso omiso de la posición del TJUE ${ }^{43}$.

\section{INJERENCIA EN EL ÁMBITO DE LA LIBERTAD Y LOS DERECHOS DE LOS JUECES}

Las acciones de la autoridad política hacia el poder judicial también afectaron directamente a los jueces como sujetos de libertades y derechos. Los instrumentos

41 Véase http://curia.europa.eu/juris/document/document.jsf?text $=\&$ docid $=221358 \&$ pageIndex $=0 \&$ doclang $=$ ES\&mode $=1$ st $\&$ dir $=$ \&occ $=$ first $\&$ part $=1 \&$ cid $=3038951($ acceso: $30 / 01 / 2021)$.

42 Véase http://curia.europa.eu/juris/document/document.jsf?text=\&docid=225141\&pageIndex $=0 \&-$ doclang $=$ ES\&mode $=1$ st $\&$ dir $=\& o c c=$ first $\&$ part $=1 \&$ cid $=3041584($ acceso: $30 / 01 / 2021)$

43 Véase C. PÉrez Bernárdez, «La Unión Europea frente a la erosión del estado de derecho: las respuestas jurídico-políticas al caso polaco», $R G D E$, vol. 40, 2016, pp. 49 y ss. 
de interferencia en la independencia judicial, así como en la libertad de expresión y asociación de jueces, inaceptables desde el punto de vista del derecho constitucional, internacional y europeo, fueron introducidos por la Ley de 20 de diciembre de 2019 de modificación de la Ley sobre el sistema de tribunales ordinarios, la Ley sobre el Tribunal Supremo y algunas otras normas como la llamada norma de acto represivo. La ley endureció radicalmente la responsabilidad disciplinaria de los jueces e impuso a los jueces obligaciones que violaban sus derechos fundamentales, como el derecho a la privacidad, la libertad de expresión y la libertad de asociación. Los cambios fueron criticados por la Comisión de Venecia ${ }^{44}$ y, en abril de 2020, la Comisión Europea inició otro procedimiento contra Polonia en relación con el cumplimiento del Estado de Derecho en virtud del art. 7 del Tratado de la Unión Europea ${ }^{45}$.

Actualmente, un juez en Polonia es disciplinariamente responsable de: delitos obvios y flagrantes contra la ley; actos u omisiones que puedan imposibilitar u obstaculizar significativamente el funcionamiento de una autoridad judicial; acciones que cuestionen la existencia de la relación laboral de un juez, la eficacia del nombramiento de un juez o la autorización de un órgano constitucional; actividades públicas incompatibles con los principios de independencia del poder judicial y de los jueces; violación de la dignidad del cargo. El mecanismo de responsabilidad disciplinaria de los jueces, basado en un alcance tan amplio de las conductas sancionables, permite el ejercicio del control político sobre el contenido de las decisiones judiciales, obligando a los jueces a fallar de acuerdo con las intenciones de la autoridad política y absteniéndose de cualquier crítica de la ley. Este tipo de solución conlleva la vulneración de la independencia judicial que sirve de garantía del ejercicio irrestricto del cargo de juez y, al mismo tiempo, es uno de los pilares del Estado de Derecho ${ }^{46}$. En la práctica, los jueces son responsables disciplinariamente por observar la ley, adherirse a la Constitución, adherirse al derecho de la Unión Europea, ejecutar las sentencias del TJUE y ser fieles a la independencia judicial.

La norma «represiva» impuso a los jueces también limitaciones en el ejercicio de las libertades y derechos garantizados en la Constitución y el Derecho europeo, que al mismo tiempo atentan contra la esencia de la independencia judicial. Se introdujo una prohibición de discutir asuntos políticos con la junta de jueces y el autogobierno de los jueces, incluida la adopción de resoluciones críticas hacia otras

44 European Commission for Democracy through Law, Poland-Urgent Joint Opinion on the amendments to the Law on organisation on the Common Courts, the Law on the Supreme Court and other Laws, CDL-PI(2020)002-e, https:/www.venice.coe.int/webforms/documents/default.aspx?pdf=CDL-PI(2020)002-e\&lang=fr (acceso: el 30/01/2021)

45 Véase https://ec.europa.eu/commission/presscorner/detail/en/ip_20_772 y https://ec.europa.eu/ commission/presscorner/detail/en/ip_21_224 (acceso: 30/01/2021).

46 Gajda-Roszczynialska, K. y Markiewicz, K., «Disciplinary Proceedings as an Instrument for Breaking the Rule of Law in Poland», Hague Journal on the Rule of Law, n. ${ }^{\circ} 12,2020$, pp. 451-483. 
autoridades de la República de Polonia, así como la responsabilidad disciplinaria de los jueces por actividad pública. Además, los jueces pasaban a estar obligados a presentar declaraciones escritas sobre la pertenencia a una asociación, la función desempeñada en el órgano de una fundación que no realiza actividades comerciales y la pertenencia a un partido político antes de ser nombrados para el cargo de juez. Teniendo en cuenta los estándares constitucionales y convencionales para la protección de la libertad de expresión, el derecho a la privacidad y la libertad de asociación, las restricciones introducidas pueden considerarse desproporcionadas y, por lo tanto, inaceptables en un Estado democrático de Derecho.

La introducción de restricciones a la libertad de expresión de los jueces (individualmente o mediante resoluciones de colegios o de autogobierno judicial) como parte del debate público sobre el poder judicial, especialmente en relación con la introducción de la base para la responsabilidad disciplinaria por «acciones de carácter político», conlleva un riesgo real de provocar un efecto desaliento (chilling effect), que en el futuro probablemente desanimará a los jueces de participar en el debate público y participar en cualquier actividad pública y social. Como se señala en la jurisprudencia del Tribunal Europeo de Derechos Humanos, el «efecto desaliento» tiene efectos no solo en la profesión de juez como tal ${ }^{47}$, sino en particular en otros jueces que deseen participar en el debate público sobre el poder judicial ${ }^{48}$. Por otra parte, no sólo la naturaleza de la sanción (penal o disciplinaria), sino el propio miedo de su aplicación, pueden tener un «efecto desaliento» en los jueces ${ }^{49}$. En la sentencia Baka, el Tribunal señaló que las cuestiones relativas al funcionamiento de la administración de justicia están dentro del ámbito del interés público, y el debate sobre él goza de un alto nivel de protección en virtud del art. 10 de la Convención, e incluso si el tema del debate tiene implicaciones políticas, no es razón suficiente para prohibir a un juez hablar sobre el caso (p. 165).

La obligación de información introducida por la norma «represiva» constituye una injerencia importante tanto en el derecho a la privacidad como en la libertad de asociación.

Realmente, se introdujo un mecanismo que permitía examinar tanto la actividad pública, como social de los jueces. La Constitución de la República y otras disposiciones legales no prohíben a los jueces ejercer la libertad de asociación o ser miembros de los órganos de las fundaciones. No se puede asumir que este tipo de actividad sea incompatible con los principios de independencia de los tribunales y de los jueces, definidos en el art. 178 párrafo 3 de la Constitución y, por tanto, exija control estatal y social. Un juez, como todo ser humano y como ciudadano, es un sujeto de libertades y derechos constitucionales y, por tanto, tiene

47 STEDH de 13 de noviembre de 2008, caso Kayasu contra Turquía.

48 STEDH de 23 de junio de 2016, caso Baka contra Hungría; STEDH de 26 de febrero de 2009, caso Kudeshkina contra Rusia.

49 STEDH de 28 de octubre de 1999, caso Wille contra Liechtenstein. 
derecho a la protección de la privacidad, que puede limitarse sólo en la medida necesaria. Si un juez, en el ejercicio de sus libertades o derechos, realiza actividades que suscitan dudas desde el punto de vista de los principios de independencia de los tribunales y jueces, la ley aplicable prevé procedimientos, en virtud de los cuales tal caso puede ser esclarecido y el juez sometido a responsabilidad legal apropiada. Por tanto, las soluciones introducidas no pueden considerarse necesarias en un Estado democrático de Derecho.

\section{RECAPITULACIÓN}

Hasta hace poco, no era cuestionada la relevancia constitucional de la separación e independencia del poder judicial y la autonomía de los jueces. Estos valores se consideraban desde hace mucho tiempo como los cánones de un Estado democrático moderno y su protección era indiscutible. Estos valores son universales y, por tanto, las normas sistémicas que los describen deben ser permanentes $^{50}$. Es lo que garantiza la estabilidad en un Estado democrático regido por la ley, donde la libertad, la justicia y la protección de los derechos individuales son de especial importancia. Los cambios en el poder judicial, aunque posibles, afectan a los ámbitos más sensibles desde el punto de vista de la división y el equilibrio de poderes, las reglas del Estado de Derecho y, lo que conviene subrayar, la seguridad jurídica de cada persona. El legislador, al introducir tales cambios, está obligado a actuar con una especial cautela constitucional. La valoración de la constitucionalidad de las modificaciones en cuestión no se refiere al «simple» cumplimiento del contenido de la constitución. El legislador debe tener en cuenta la profundidad de los cambios, el momento de su implantación, el número de modificaciones, la vacatio legis adoptada, y los efectos sistémicos, organizativos, personales y de competencia derivados de estos cambios para la independencia del poder judicial. La introducción de numerosos cambios en poco tiempo y en relación con muchos aspectos del funcionamiento del poder judicial conduce a su desestabilización, lo que amenaza el estatus constitucional de los jueces y, en consecuencia, los derechos y libertades de las personas ${ }^{51}$.

La disputa sobre el poder judicial demostró con claridad que el modo de elección de los jueces es crucial para los parlamentarios, y el impacto sobre la composición de los tribunales sirve principalmente para la elección de sus «propios» jueces y tiene poco que ver con el principio de separación de poderes. Por esta razón, era natural esperar que el Presidente, para quien la Constitución prevé un papel del órgano responsable de su protección, tomara medidas para prevenir

50 Vid. Piotrowski, R., «Konstytucyjne granice reform sądownictwa», Krajowa Rada Sądownictwa. Kwartalnik, n. ${ }^{\circ}$ 2, 2017, pp. 5 y ss.

51 Piotrowski, R., «Sędziowie i granice władzy demokratycznej w świetle Konstytucji RP», Ruch Prawniczy, Ekonomiczny i Socjologiczny, n. ${ }^{\circ}$ 1, 2018, p. 228. 
las crisis constitucionales. Desafortunadamente, el Presidente de la República no cumplió este papel.

A la vista de los cambios introducidos, conviene distinguir entre la política actual de los gobernantes, que consiste en modificar, mejorar o adecuar las reglas de funcionamiento del poder judicial a los cambios de realidad y a las necesidades sociales, y la revisión de los fundamentos del sistema en el que se basa el poder judicial. Tal distinción permite constatar que la reforma de las normas de funcionamiento del Tribunal Supremo, el Consejo Nacional de la Magistratura, el Tribunal Constitucional y los tribunales excede claramente de lo que sería la normal libertad regulatoria del legislador, especialmente en el ámbito de la especial posición del poder judicial y el carácter garantizador del derecho a un juicio justo. La independencia del poder judicial determina un límite infranqueable.

Title: The (In)Dependence of the Judiciary in Poland. On the Subordination of Judges to Political Power

ABSTRACT: The text is an analysis of changes and actions made in Poland within the judiciary. These changes concerned the most sensitive areas from the point of view of the separation of powers and the rule of law. Within two years, several dozen changes were introduced, covering many aspects of the functioning of the judiciary, which led to its destabilization, threatened the constitutional status of judges and, as a result, the rights and freedoms of the individual.

RESUMEN: El texto aborda las últimas reformas del poder judicial y las influencias que a través de las mismas pretender el poder político obtener en aquel. En dos años, se introdujeron varias decenas de cambios que abarcaban muchos aspectos del funcionamiento del poder judicial, lo que llevó a su desestabilización, amenazó el estatus constitucional de los jueces y, como resultado, los derechos fundamentales.

KEY WORDS: Constitutional crisis, judiciary, independence, constitutional law, separation of powers.

Palabras Clave: Crisis constitucional, poder judicial, independencia, derecho constitucional, separación de poderes.

FECHA DE RECEPCIÓN: 16.12.2020

FECHA DE ACEPTACIÓN: 26.01.2021 